\title{
Middle Cranial Fossa Anatomy and the Origin of Modern Humans
}

\section{Citation}

Bashir, Markus, Antonio Rosas, Daniel E. Lieberman, Paul O'Higgins. 2008. Middle cranial fossa anatomy and the origin of modern humans. The Anatomical Record 291(2): 130-140.

\section{Published Version}

doi:10.1002/ar.20636

\section{Permanent link}

http://nrs.harvard.edu/urn-3:HUL.InstRepos:3716473

\section{Terms of Use}

This article was downloaded from Harvard University's DASH repository, and is made available under the terms and conditions applicable to Other Posted Material, as set forth at http:// nrs.harvard.edu/urn-3:HUL.InstRepos:dash.current.terms-of-use\#LAA

\section{Share Your Story}

The Harvard community has made this article openly available.

Please share how this access benefits you. Submit a story.

Accessibility 


\title{
Middle Cranial Fossa Anatomy and the Origin of Modern Humans
}

\author{
MARKUS BASTIR, ${ }^{1 *}$ ANTONIO ROSAS, ${ }^{1}$ DANIEL E. LIEBERMAN, ${ }^{2}$ \\ AND PAUL O'HIGGINS ${ }^{3}$ \\ ${ }^{1}$ Department of Paleobiology, Museo Nacional de Ciencias Naturales, CSIC, c/Jose \\ Gutierrez Abascal 2; 28006; Madrid, Spain \\ ${ }^{2}$ Departments of Anthropology and Organismic and Evolutionary Biology, Harvard \\ University, Cambridge, Massachusetts \\ ${ }^{3}$ Functional Morphology and Evolution Unit, Hull York Medical School, The University of \\ York, Heslington, York, United Kingdom
}

\begin{abstract}
Anatomically, modern humans differ from archaic forms in possessing a globular neurocranium and a retracted face and in cognitive functions, many of which are associated with the temporal lobes. The middle cranial fossa (MCF) interacts during growth and development with the temporal lobes, the midface, and the mandible. It has been proposed that evolutionary transformations of the MCF (perhaps from modification of the temporal lobes) can have substantial influences on craniofacial morphology. Here, we use three-dimensional (3D) geometric morphometrics and computer reconstructions of computed tomography-scanned fossil hominids, fossil and recent modern humans and chimpanzees to address this issue further. Mean comparisons and permutation analyses of scaled 3D basicranial landmarks confirm that the MCF of Homo sapiens is highly significantly different $(P<0.001)$ from $H$. neanderthalensis, $H$. heidelbergensis, and Pan troglodytes. Modern humans have a unique configuration with relatively more anterolateral projection of the MCF pole relative to the optic chiasm and the foramen rotundum. These findings are discussed in the context of evolutionary changes in craniofacial morphology and the origins of modern human autapomorphies. In particular, the findings of this study point to variations in the temporal lobe, which, through effects on the MCF and face, are central to the evolution of modern human facial form. Anat Rec, 291:130-140, 2008. ๑ 2008 Wiley-Liss, Inc.
\end{abstract}

Key words: lateral cranial base; human evolution; temporal lobes; sphenoid; 3D reconstructions; geometric morphometrics

\begin{abstract}
Anatomically modern humans differ craniodentally from all other, extinct, hominins in many ways (see Day and Stringer, 1982; Lahr, 1996; Stringer, 2001), most of which relate to two general suites of derived features: a more globular neurocranium and a more retracted face (Lieberman et al., 2002). One persistent, important question is the extent to which these derived features are related to increases in the relative and absolute increase in size (encephalization) of the brain, particularly of the telencephalon (Dabelow, 1931; Weidenreich, 1941; Biegert, 1963; Gould, 1977; Holloway et al., 2004).

During human evolution, the brain underwent a volumetric increase in neocortex size in the frontal,
\end{abstract}

Grant sponsor: Spanish Ministry of Education and Science; Grant number: CGL-2006-02131; Grant sponsor: SYNTHESYS; Grant sponsor: EVAN (European Virtual Anthropology Network); Grant number: MRTN-CT-2005-019564.

*Correspondence to: Markus Bastir, Department of Paleobiology, Museo Nacional de Ciencias Naturales, CSIC, c/Jose Gutierrez Abascal 2; 28006; Madrid, Spain. Fax: 34-91-5645078. E-mail: mbastir@mncn.csic.es

Received 10 July 2007; Accepted 7 November 2007

DOI 10.1002/ar.20636

Published online in Wiley InterScience (www.interscience. wiley.com). 
temporal, parietal, and occipital lobes, which has traditionally been associated with increased cognitive complexity (Deacon, 1997; Semendeferi and Damasio, 2000; Rilling and Seligman, 2002; Rilling, 2006). Recent comparative allometric studies have shown that the human temporal lobes, in particular, have increased relative to other regions of the cerebrum when compared with nonhuman primates (Semendeferi and Damasio, 2000; Rilling and Seligman, 2002). The temporal lobes, which occupy on average $18.1 \%$ of total brain volume in humans (Semendeferi and Damasio, 2000) consist of anatomical units, such as the amygdala, the hippocampus, and the rhinal cortex. Grossly speaking, the primate temporal lobe is functionally divided into several regions of which the superior temporal gyrus has been associated with auditory processes, the inferior temporal gyrus with visual processes, and the temporal pole with social behavior (Rilling and Seligman, 2002). Functional magnetic resonance imaging (MRI) studies have shown that the amygdala is strongly involved in processing of fearful and dangerous experiences (Zola et al., 2000), but altogether it seems that the human medial temporal lobe is relatively similar to that of other primates in general function.

The lateral and caudal parts of temporal lobes, however, are thought to be very different. This is because of human speech. The expanded lateral language areas (Wernicke's area) have shifted the visual object recognition pathway into a more laterocaudal position in humans when compared with other primates (Ungerleider et al., 1998). From a neuroanatomical point of view, recent research has shown absolute and relative increase of white matter in humans compared with apes, which likely consists of axons that link temporal and frontal cortical areas (Rilling and Seligman, 2002; Rilling, 2006). These neuroanatomical and cognitive modifications that potentially increase the spatial demands of the temporal lobe might well have influenced the evolution of modern human craniofacial morphology.

Nineteenth and early twentieth century craniology laid the foundations of a classic line of research, in which morphological changes of the brain are hypothesized to impact on the morphology of the basicranium and the face (Dabelow, 1931; Weidenreich, 1941; Hofer, 1954; Biegert, 1957; Moss, 1962; Enlow, 1975; Gould, 1977; Shea, 1985; Ross and Ravosa, 1993; Ross and Henneberg, 1995; Spoor, 1997; Lieberman, 1998; Lieberman and McCarthy, 1999; McCarthy and Lieberman, 2001; Lieberman et al., 2000, 2004; Ross et al., 2004). These and other studies have mainly addressed factors influencing the evolution and variation of the midline basicranial angle between pre-sellar and post-sellar components. They also addressed the relative proportions of midline basicranial structures and the potential relations between variations in these and variations in facial morphology. While the underlying key idea was that encephalization leads to basicranial flexure in the midline, recent developmental studies are increasingly challenging this view. Recent developmental evidence in primates points to a bidirectional relationship of physical brain expansion, basicranial development, and growth under genetic influences and other factors, which are responsible for eventual basicranial morphology (Jeffery and Spoor, 2002; Jeffery 2003, 2005; Jeffery et al., 2007; Hallgrimsson et al., 2007).
Enlow's counterpart principle (1990) suggests a spatial correspondence between anatomical structures separated by the posterior maxillary (PM) plane. One group of structures comprises the frontal lobes, the anterior cranial base and floor, the ethmomaxillary complex (the "facial block"; Lieberman et al., 2000; McCarthy and Lieberman, 2001), and the mandibular corpus; the other comprises the temporal lobes, the posterior base, the middle cranial fossa, and the mandibular ramus (Bastir et al., 2004). Recent geometric morphometric studies have addressed Enlow's counterpart principle, focusing on the more complex off-midline basicranial morphology and its possible interactions with facial morphology (Bastir et al., 2004, 2006; Bastir and Rosas, 2005). The results suggest that the lateral basicranial components, that is, the anterior and middle cranial fossae, are particularly integrated with facial structures. Thus, spatial modifications at the lateral basicranium likely have consequences for the spatial arrangement of facial structures (Bastir et al., 2004).

The developing cranial base is also influenced by the face (Biegert, 1957; Bastir, 2004; Jeffery, 2005; Rosas et al., 2006), although facial growth has less influence on cranial base shape in higher primates and humans. The brain has especially pronounced effects on basicranial morphology, in large part because the endocranial fossae are part of the brain's skeletal capsule (Hofer and Tigges, 1963; Moss, 1972). The inferior surface of the brain and the superior surface of the cranial base have well fitting and fairly complementary "mirror-like" morphologies (Richtsmeier et al., 2006; Fig. 1a,b), although they are slightly blurred by dura and pia mater, cerebrospinal fluid, and other intracranial structures such as vessels and nerves.

In relation to the effects of neurocranial anatomy on facial form there has been special interest in the middle cranial fossae (MCF; Fig. 1c). These have a central position in the cranium, lying behind the orbits and midface, and being anatomically related to the mandibular rami externally and to the area of cranial base flexion in the midline (Enlow, 1975; Lieberman et al., 2000, 2002; Bastir et al., 2004, 2006; Bastir and Rosas, 2005). Variations in MCF morphology, which potentially derive from variations in temporal lobe morphology, can thus influence facial shape and positioning relative to other cranial structures.

It has been argued that several key modern human autapomorphies, including facial retraction and a short oropharynx derive, in part, from a more flexed cranial base, and a relatively wider or larger middle cranial fossa (Lieberman, 1998, 2000; Spoor et al., 1999; Lieberman et al., 2000, 2002). To summarize, in addition to the classic view that a more flexed cranial base causes the face as a whole to rotate more ventrally it has been argued by Lieberman and co-workers, that this also leads to a decrease of the projection of the upper face, and a shortening the oropharynx (Lieberman et al., 2000; McCarthy and Lieberman, 2001).

Although most studies of human cranial development and evolution have focused on the relationship between brain form and the morphology of the basicranium in the midline, variations in MCF morphology are also important in terms of changes to the lateral (off-midline) basicranium (Bastir et al., 2004, 2006; Bastir and Rosas, 2005). Additionally, aspects of off-midline basicranial 

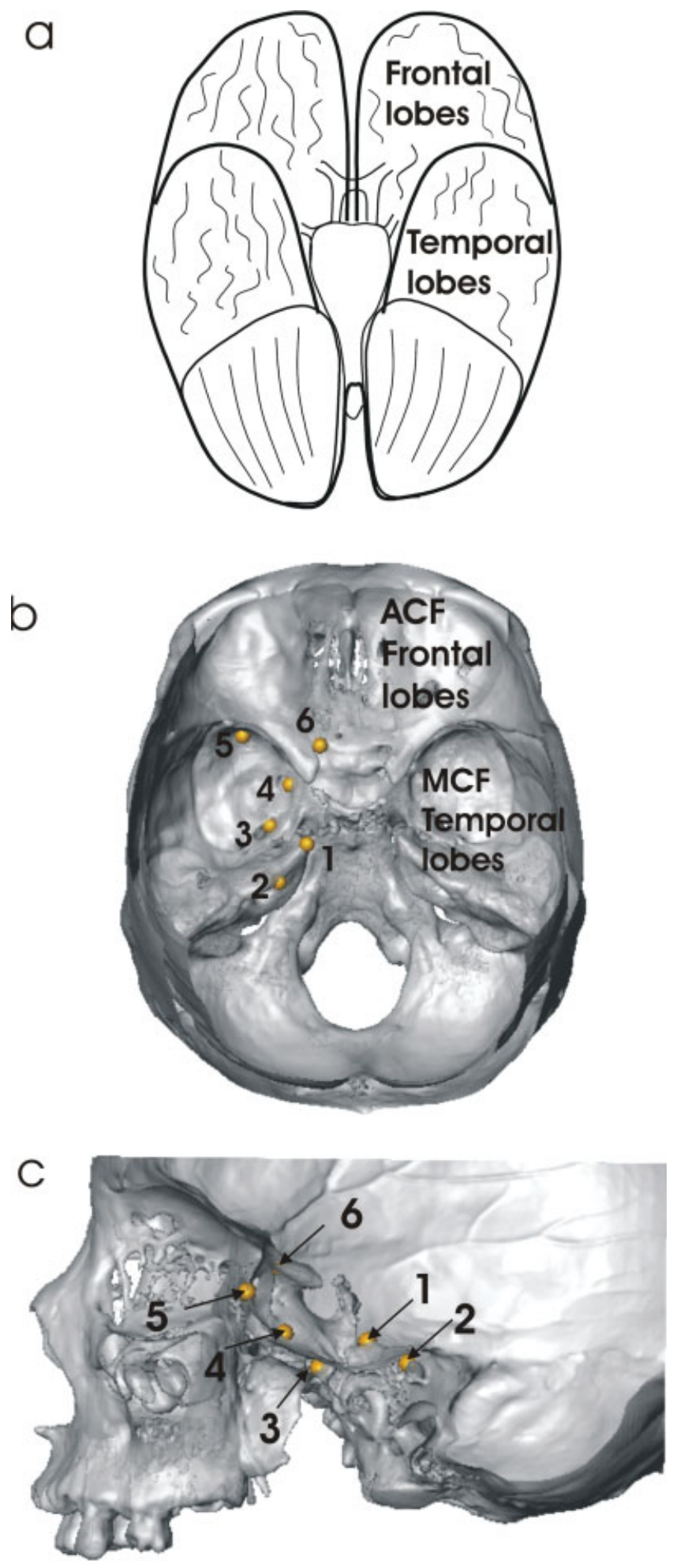

Fig. 1. a: Relationships between the brain and the basicranium; the inferior aspect of the brain matches. b: Superior view of the complete basicranium [see three-dimensional (3D) landmarks described in the Material and Methods section]. c: Lateral view of the middle cranial fossa showing the three-dimensional landmarks. morphology have been examined in relation to human evolution (Maier and Nkini, 1984; Seidler et al., 1997; Spoor et al., 1999; Lieberman et al., 2002; Baba et al., 2003). While all these studies have suggested that the $\mathrm{MCF}$ and/or the associated temporal lobes might play an important role in human craniofacial evolution no comprehensive analysis of $3 \mathrm{D}$ variations in form of the MCF of living and extinct members of the genus Homo has yet been undertaken.

Maier and Nkini (1984) compared, using computed tomography (CT) scans, the midline and lateral basicranial morphology of OH9 and modern humans. They found a flatter lateral cranial base in $\mathrm{OH} 9$, suggesting decreased depth of the MCF in $H$. erectus compared with modern humans. The analysis of stereolithographs of Middle Pleistocene hominids by Seidler et al. (1997) reported "laterally flared temporal lobes" and a relatively narrow MCF in Kabwe and Petralona. The geometric morphometric analysis of the cranial base by Spoor et al. (1999), which included a few off-midline cranial landmarks, suggested a possible expansion of the temporal lobes into the MCF in modern humans compared with Middle Pleistocene hominids, but 3D MCF anatomy was not examined, because landmarks were projected into the sagittal plane. Baba et al. (2003) compared CT scans from one $H$. erectus cranium (Sambungmacan 4) with a small sample of modern humans ( $\mathrm{n}=$ 9 ), finding that the former had a relatively shorter MCF both in the sagittal plane and more laterally.

The most detailed analysis to date to consider lateral cranial base anatomy (Lieberman et al., 2002) found that the MCF in modern humans is approximately $20 \%$ wider relative to cranial size than in archaic humans (H. neanderthalensis and $H$. heidelbergensis s.l.), suggesting that this feature is a potentially important autapomorphy of modern humans. However, the finding is based on very small samples with a limited number of landmarks and few off-midline from the MCF. The potential importance of these findings with respect to understanding the evolution of modern human cranial form means that evolutionary variations in MCF form require more detailed examination.

The aim of the present study is to provide a detailed comparison of the anatomical relationships of off-midline MCF landmarks in a broad sample of modern humans (from Africa, Europe, Asia, Australia, and North America) and a range of fossil hominins and chimpanzees. The anatomical relationship between the anterior pole of the MCF, which marks the posterior limit of the upper lateral face, and other MCF structures is examined for evidence of a derived modern human morphology consistent with the differences between modern human facial form, positioning and especially retraction relative to other hominids. The study tests the null hypothesis that the shape of the MCF does not differ significantly between anatomically modern $H$. sapiens and other species of Homo.

\section{MATERIALS AND METHODS}

The landmarks used in this study were selected to characterize middle cranial fossa morphology but with due regard for the preservation of fossil basicrania and repeatability of digitization (see intraobserver error below). Six 3D landmark ( $\mathrm{lm}$ ) coordinates were digitized 
TABLE 1. Fossil data ${ }^{a}$

\begin{tabular}{lll}
\hline Fossil & \multicolumn{1}{c}{ Taxon } & Data source \\
\hline Sts5 & A. africanus & CT \\
OH9 & H. erectus/ergaster & CT \\
KNM-ER 3733 & H. erectus/ergaster & CT \\
KNM-ER 3883 & H. erectus/ergaster & CT \\
Bodo & H. heidelbergensis s.l. & CT \\
Kabwe & H. heidelbergensis s.l. & CT \\
Petralona & H. heidelbergensis s.l. & STL \\
Arago 21 & H. heidelbergensis s.l. & CT \\
Guattari1 & H. neanderthalensis & CT \\
Gibraltar1 & H. neanderthalensis & Original \\
Saccopastore2 & H. neanderthalensis & Cast \\
Singa & H. sapiens & CT \\
Skuhl V & H. sapiens & CT \\
Mladec 1 & H. sapiens & CT \\
\hline
\end{tabular}

${ }^{\mathrm{a}} \mathrm{CT}$, computer tomography; STL, stereolithography.

from virtual $3 \mathrm{D}$ computer reconstructions of the CT data (Fig. 1): $\operatorname{lm} 1$, petrosal apex (most medial point); $\operatorname{lm} 2$, internal acoustic porus (superomedial border); $\operatorname{lm} 3$, foramen ovale (most medial point); $\operatorname{lm} 4$, foramen rotundum (most medial point); $\operatorname{lm} 5$, anterior MCF-point (maximal $3 \mathrm{D}$ curvature of greater sphenoid wings); and $\operatorname{lm} 6$, foramen opticum (anterolateral border). The reconstructions were generated with high resolution, which enabled us also to clearly identify smaller basicranial foramina. In fossils, in which foramina were filled by sediment, landmarks were digitized on the CT slices.

We used CT-scanned crania of 22 Liberian chimpanzees (Pan troglodytes verus, housed at the Peabody $\mathrm{Mu}-$ seum, Harvard University) and 51 cranial bases of recent modern humans from Africa, Asia, Australia, and North-America (from the Penn Cranial CT collection, Penn State University) and from Europe (Oloriz-collection, Virtual CT collection of the Museo Nacional de Ciencias Naturales, Universidad Complutense de Madrid). Landmark data were also obtained from 14 fossils (Table 1).

\section{GEOMETRIC MORPHOMETRICS}

We used standard procedures of Procrustes based geometric morphometric methods to analyze variations in the form (size and shape) of the landmark configurations (Rohlf and Slice, 1990; Bookstein, 1991; Dryden and Mardia, 1993; O’Higgins, 1999; Zelditch et al., 2004). The 3D landmark configurations were submitted to a generalized Procrustes analysis (GPA; Rohlf and Slice, 1990) which translates, rotates, and scales (to unit centroid size) all specimens to minimize the sum of squared landmark deviations from the estimate of the sample mean leading to a common registration (Kendall, 1989). Procrustes residual shape coordinates as well as centroid size were obtained for subsequent statistical analyses (Bookstein, 1991; O’Higgins, 2000; Zelditch et al., 2004). The metrics of shape space are Procrustes distances (d) computed as the square root of the summed squared distances between homologous landmarks of Procrustes registered landmark configurations.

The differences in shape between pairs of landmark configurations were further evaluated independent of registration using transformation grids computed using thin plate splines (Bookstein, 1991; O'Higgins, 2000; Zelditch et al., 2004). The TPS function is used to smoothly interpolate a reference configuration and its accompanying surface into a target configuration and surface. Registration independence means that transformation grids, rather than superimposed images or wireframes, are the preferred way of visualizing shape differences. The thin plate splines were also used to warp landmarked images as an aid to interpretation.

Missing data presented a problem common to many studies of fossils. Our approach in the present study is to estimate them. There are several statistical and biological considerations to bear in mind in carrying out such estimations. Thus, Gunz et al. (2004) differentiated between statistical, geometric, and anatomical reconstructions. Among the statistical approaches to reconstruction they used, multiple multivariate regressions proved preferable to replacement of missing landmarks by the mean when reference populations were available. The geometric approach to reconstruction uses thinplate splines to estimate missing landmarks by minimizing the bending energy in the transformation of a complete reference configuration into the (incomplete) target configuration (Gunz et al., 2004). Whether statistical or geometric approaches are used to estimate missing data, anatomical knowledge should inform the appraisal of quality of estimation. Further morphological integration is an important consideration because, in highly integrated structures (e.g., where there are missing data within modules), the quality of prediction of missing landmarks is likely higher than when prediction is attempted between different modules. In the present study, missing data had to be estimated in the $H$. heidelbergensis s.l. sample [Petralona (lm 6); Arago 21 (lms 1, 2)]. Following Gunz et al. (2004), these were estimated with satisfactory anatomical results, using the regression method computed by Morpheus et al. (Slice, 1998) and reference data from specimens of the Neanderthal lineage $(H$. heidelbergensis s.l. and $H$. neanderthalensis).

Measurement error can be evaluated by various methods (von Cramon-Taubadel et al., 2007). Von Cramon-Taubadel's approach is concerned with localizing error, that is, estimating how well particular landmark coordinates are obtained. In the present study, which is concerned with overall shape variability, we repeatedly digitized all landmarks on one modern human specimen (specimen 794 of the Oloriz collection) on five separate occasions to assess the error in estimating the shape of the configuration as a whole. The ratio of squared Procrustes distances from the mean within the repeats to that within the modern human sample is 0.064. A minimum spanning tree based on the Procrustes distance matrix clustered the repeated specimens with each other rather than with other specimens. The largest Procrustes distance between repeats $(d=0.05)$ is less than the smallest Procrustes distance $(d=0.08)$ within the modern human sample. Furthermore, when the landmark data from repeats are subjected to GPA/PCA (see below) together with the landmark data from the human sample, they group closely together in the relevant PC plots. We used NTSYSpc 2.1 and morphologika ${ }^{2}$ for the calculations of intraobserver error. 


\section{Statistical Analyses}

To explore patterns of MCF landmark variation a principal components analysis (PCA) of tangent projected shape coordinate data was carried out using morphologika (O'Higgins, 2000; www.york.ac.uk/res/fme/ resources/software.htm). Aspects of shape variation represented by PC axes were explored, and TPS transformations of $3 \mathrm{D}$ surface models were used to visualize evolutionary transformations between early hominins and modern humans (Fig. 2). Permutation tests (Good, 1993) were used to assess the significance of differences between species means. Significant differences are visualized by computing and superimposing the landmark configurations of species means. Then thin-plate splines were used to warp the landmarks plus 3D surface data (from the CTs) for an exemplar (close to the mean) in each species to the mean landmark configuration in that species, thus estimating the species mean surface of modern humans and then warping this to the comparison species' mean (that is $H$. neanderthalensis, $H$. heidelbergensis sensu lato, P. troglodytes verus) to visualize differences (Fig. 3). Finally, individual differences were used to compute, using thin-plate splines, transformation grids (Fig. 4) to aid interpretation and localization of differences (Bookstein, 1991; Zelditch et al., 2004). These surface warpings and visualizations were carried out using Amira 4.1 and morphologika ${ }^{2}$.

\section{RESULTS}

To test if there are significant size differences among the landmark configurations of modern and fossil hominins, an analysis of variance of centroid size (CS) among the groupings was computed, revealing significant differences $[F(6,71)=18.096 ; P<0.001]$. However, post hoc tests of pairwise comparisons showed that only chimpanzees $(\mathrm{CS}=38.8)$ possess a significantly smaller MCF landmark configuration $(P<0.001)$ than all hominins with no significant differences in CS among the means of the hominin species (H. s. 44.8; H. n. 46.6; H. h. s.l. 47.6; H. e. s.l. 47.8). For this reason, subsequent analyses focus on shape alone.

Figure 2a plots PC 1 vs. PC 2 from the PCA (Table 2) of the six landmarks from all specimens after GPA and tangent projection. In this subspace that accounts for most of the interesting variation in the context of our study (58\% of total variance), the chimpanzees are toward the right (positive) extreme of PC 1 and the modern humans toward the opposite extreme. Most of the fossils are located between the modern samples on PC1, with the Neanderthals forming a distinct group along with $H$. heidelbergensis s.l., $H$. erectus s.l., $H$. ergaster, and $A$. africanus on the combination of PC1 and PC2. The fossil a.m. H. sapiens are well within the range of recent modern humans. The four fossils attributed to $H$. heidelbergensis s.l. occupy a somewhat intermediate position between the early hominids (Sts5, OH9, KNM-ER 3733, KNM-ER 3883) and the Neanderthals. Overall, modern humans, even in this plot of the PC1-2 subspace, are clearly separated from earlier hominins. Indeed higher PCs are uninformative with respect to differences between modern and fossil hominins.
The apects of shape variability represented by PC1 principally relate to the relative size of the MCF due to anterolateral displacement of $\operatorname{lm} 5$ with respect to $\operatorname{lm} 4$ and $\operatorname{lm} 6$. Thus, in humans, the most anterior landmark is $\operatorname{lm} 5$, whereas in chimpanzees $\operatorname{lm} 5$ is at the same level as lm6. PC2 largely represents variations in the positioning of $\operatorname{lm} 6$ relative to other landmarks. LM6 is relatively superior, medial, and posterior in early hominins (positive PC 2 scores) and more inferior, lateral, and anterior in modern humans (negative PC 2 scores). In top view, early hominins are characterized by quadratic MCF shape, whereas modern humans show elongation.

The aspects of shape that underlie evolutionary changes in the PC1-PC2 subspace from early Homo (positive scores on PC 2; reference ["ref" in Fig. 2a]) to modern humans (negative scores on PC 1; target ["tar" in Fig. 2a]) are visualized as surface warps in Figure 2c-d. These are based on the landmark configurations shown in Figure $2 b$ and transform the MCF surface of ER 3733 (Fig. 2d), warping it between the positive extreme of PC2 (close to KNM-ER 3733,) and the mean of the modern human scatter (Fig. 2e) on these PCs. This warping (compare Fig. 2d with 2e) shows that, in modern humans compared with "ergaster/erectus," there is a marked forward and lateral expansion of the anterior part of the MCF relative to the optic and maxillary nerve foramina.

Similar differences, although subtly different in nature and degree (see below) are observed in mean shape comparisons of modern humans with other, extinct, species of Homo, and chimpanzees (Fig. 3). The mean shape comparisons between $H$. sapiens and other hominid groups as assessed by permutation tests are all highly significant (Table 3). No significant differences were found between Neanderthals and the Middle Pleistocene humans. This may either reflect smaller sample sizes or lack of any real difference in this basicranial area. This should be borne in mind in assessing subsequent comparisons of these groups (Fig. 4). The differences between modern humans are visualized in Figure 3 by warping and comparing the mean MCF surface derived from modern humans to the mean of each species. These warps indicate that modern humans possess a particularly elongated MCF with significant forward and lateral positioning of the anterior MCF point (indicated by the double-headed arrow) relative to the basicranial foramina and petrosal apex when compared with other species mean shapes.

These apparent differences were further examined by use of 2D transformation grids in the parasagittal planes within the MCF. Figure 4 illustrates these computed between the following: Kabwe (reference) and a modern human (target; Fig. 4a), Kabwe and Guattari 1 (Fig. 4b), and Guattari 1 and a modern human (Fig. 4c). These transformations between single specimens do not take into account individual variation, but the expansion of the thin-plate spline in the area of $\operatorname{lms} 4,5$, and 6 reflects the mean shape differences shown in Figure 3, highlighting the finding that forward projection of the anterior MCF point (also known as the PM point, see arrows in Fig. 4a,c) relative to other landmarks is an apparent autapomorphy of modern humans. No such difference is observed in comparing Kabwe and Guattari (Fig. 4b). 


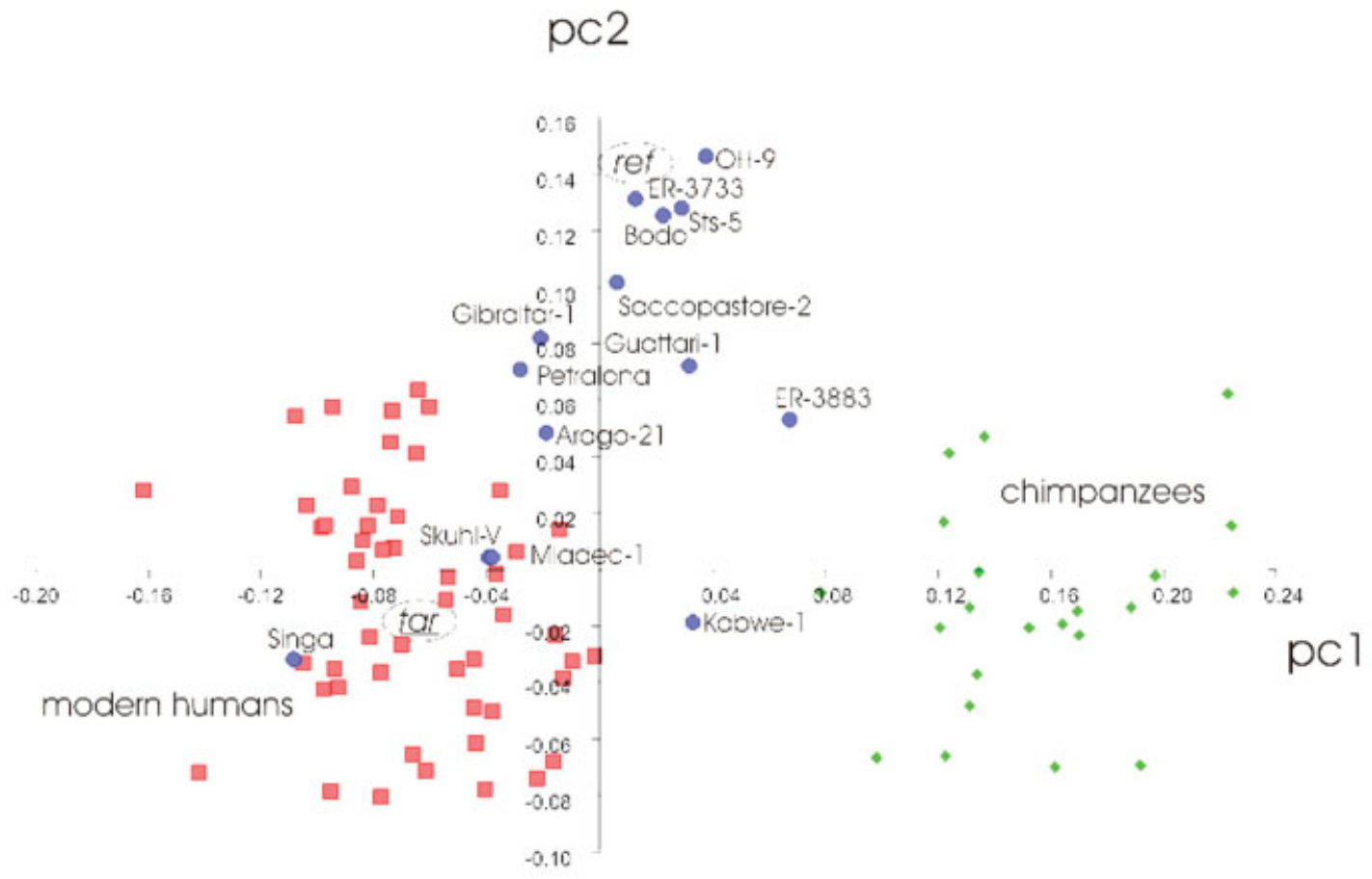

b

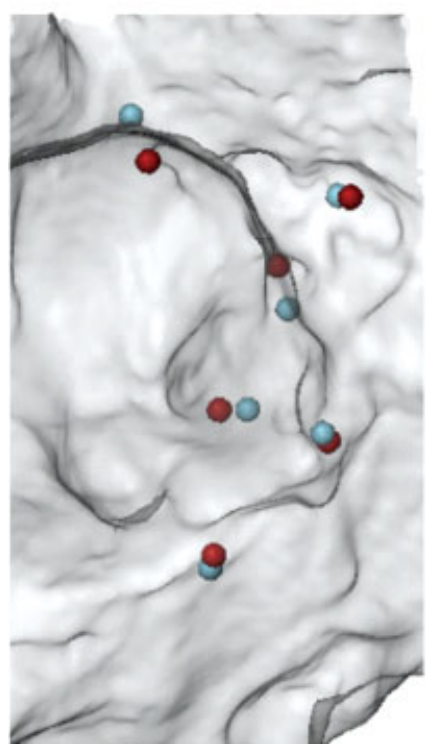

C ref

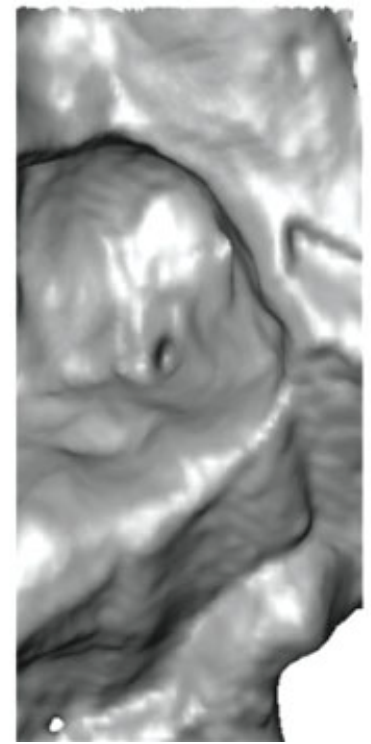

d<smiles>[GeH3]</smiles>

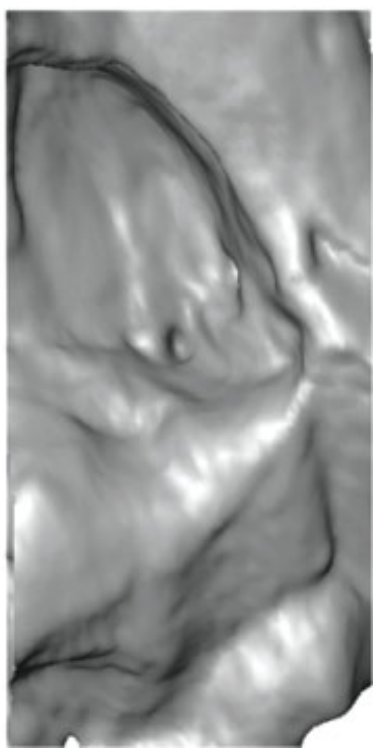

Fig. 2. Principal components analysis (PCA) and three-dimensional (3D) warps illustrating middle cranial fossa (MCF) shape differences between earlier hominids $(H$. erectus/ergaster) and modern humans; a: Scatterplot of PC1 vs. PC2 scores. PC1 separates the chimpanzee (green diamonds) and the modern human samples (orange squares). Other hominins (blue circles) are intermediate. Fossil modern humans Singa, Skuhl-V, and Mladec-1 plot well within the recent modern human range. PC2: KNM ER-3733, OH-9 and Sts-5 plot at the posi- tive extreme. Neanderthals are separated from the modern humans. $H$. heidelbergensis (sensu lato) specimens are intermediate between early hominids and modern humans. b: Procrustes registered landmarks of reference (_ref_; dark-red Ims) and target (_tar_; light-blue Ims), c,d: Reference surface produced by warping three-dimensional (3D) reconstruction of KNM-ER 3733 to reference landmarks (c) and to the landmark configuration of the target (d). 
a

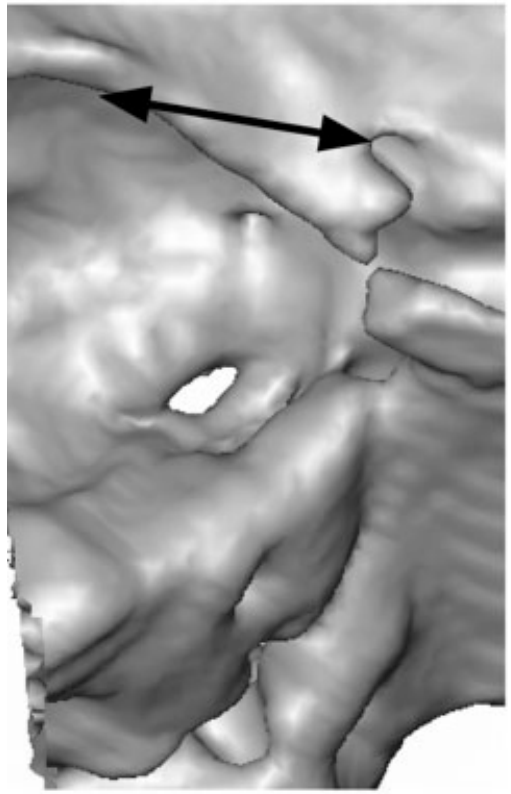

H. sapiens

C
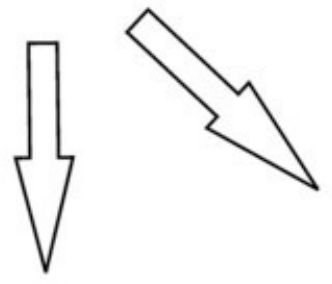

d

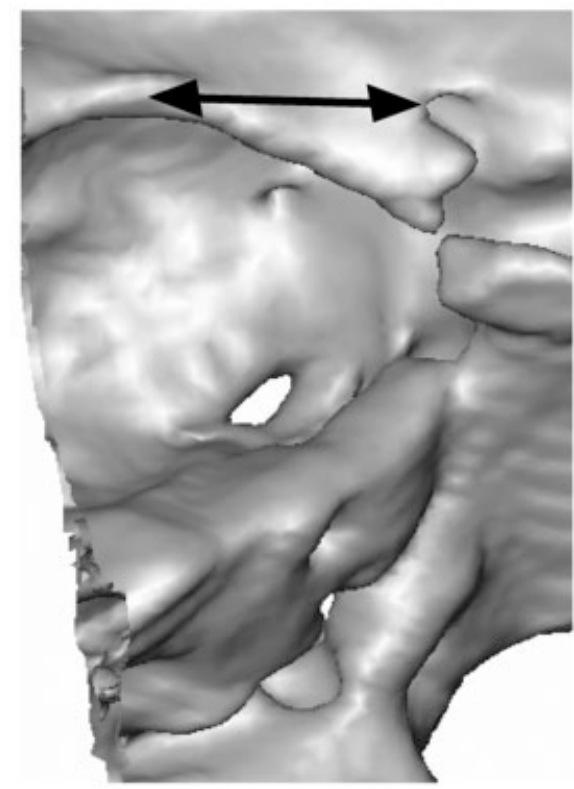

H. heidelbergensis s.I. b

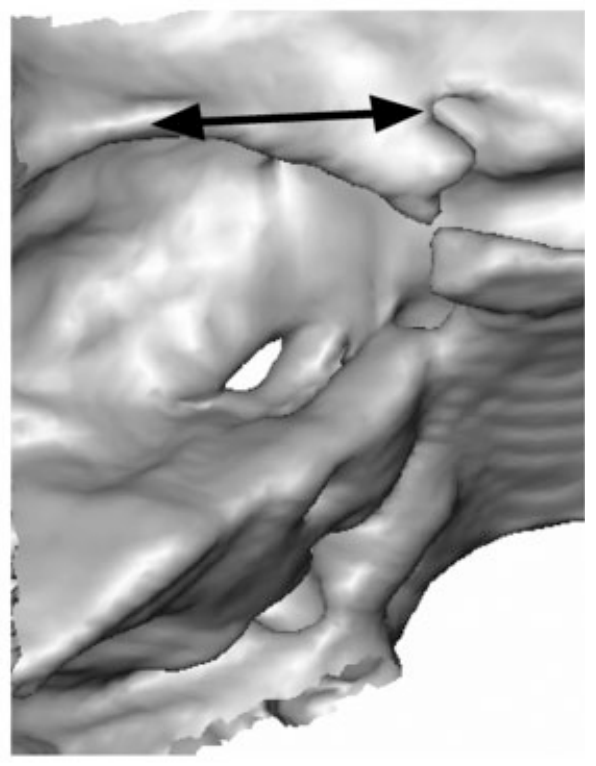

H. neanderthalensis

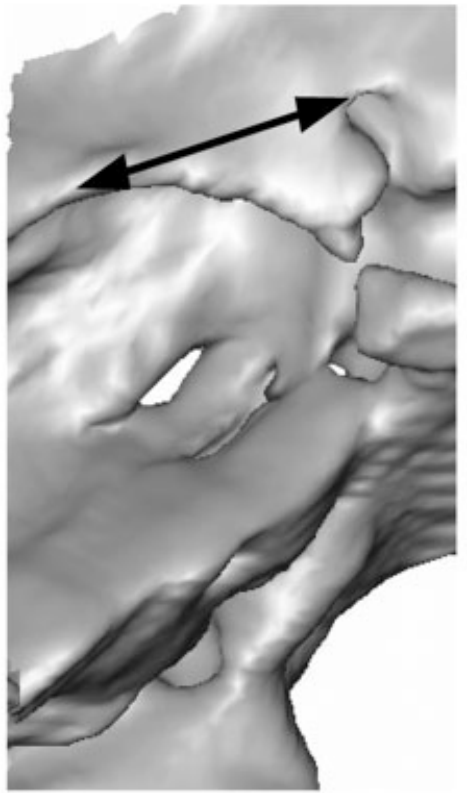

P. troglodytes

Fig. 3. a-c: Mean shape comparisons as three-dimensional (3D) surface warps of a human middle cranial fossa (MCF) surface model to the mean shapes of modern humans (a), Neanderthals (b), $H$. heidelbergensis s.I (c). d: chimpanzees. Note the different anatomical relations between the anterior MCF pole and the optic and maxillary nerve foramina. 

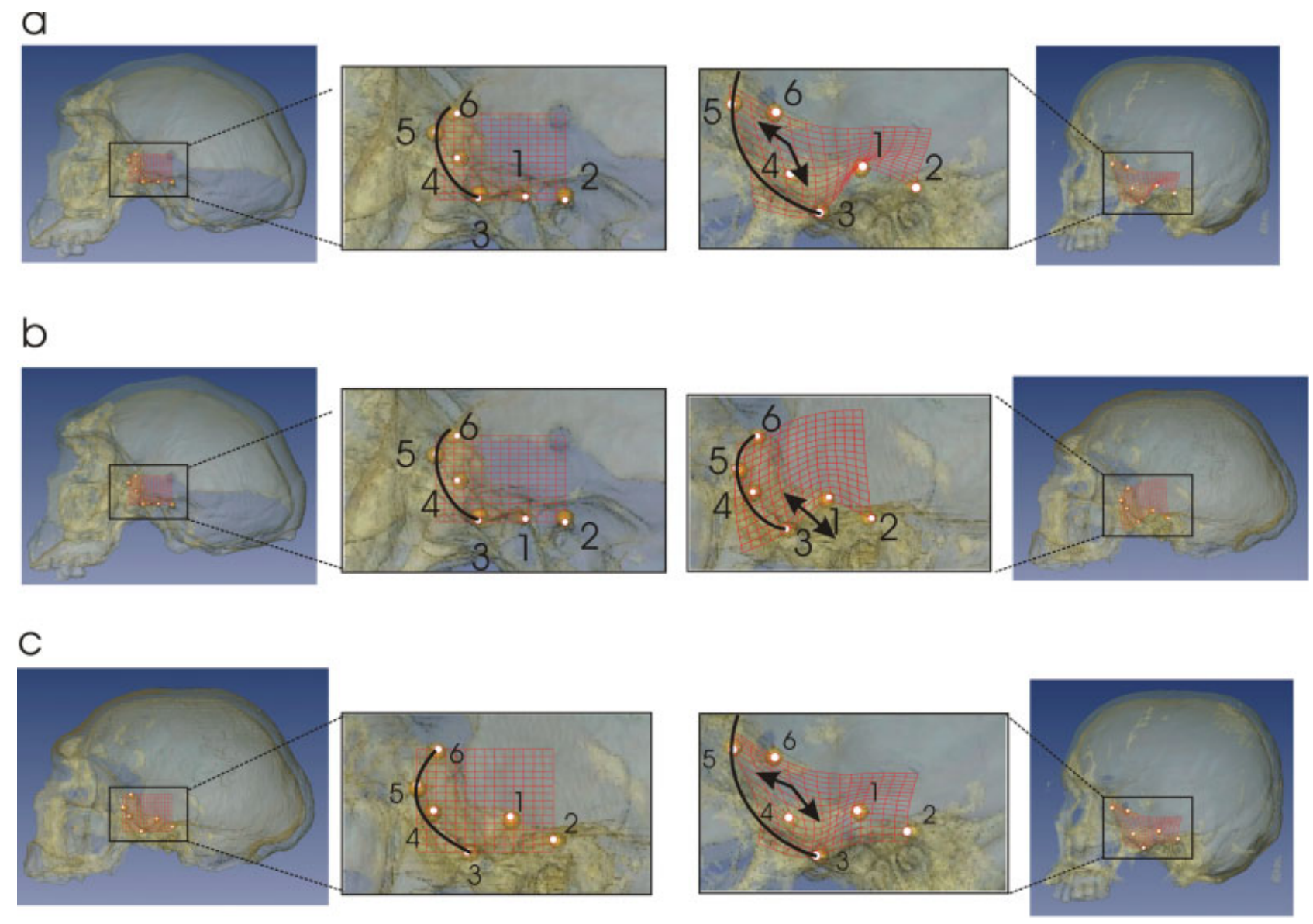

Fig. 4. Transformation grids between lateral views of individual fossils. a: Kabwe and a modern human skull. b: Kabwe and Guattari. c: Guattari and modern human skull. Note the extreme anterosuperior shift of the anterior MCF point (Im5) with respect to the optic canal (Im6) and the foramen rotundum (Im4) in comparisons of fossils and modern humans.

TABLE 2. Descriptives of principal components analysis

\begin{tabular}{lccc}
\hline PC & Eigenvalue & \% of variance & Cumulative $\%$ \\
\hline PC1 & $1.01 \mathrm{E}-02$ & 0.45 & 0.45 \\
PC2 & $2.68 \mathrm{E}-03$ & 0.12 & 0.57 \\
PC3 & $1.99 \mathrm{E}-03$ & 0.09 & 0.66 \\
PC4 & $1.39 \mathrm{E}-03$ & 0.06 & 0.72 \\
PC5 & $1.29 \mathrm{E}-03$ & 0.06 & 0.78 \\
PC6 & $1.25 \mathrm{E}-03$ & 0.06 & 0.83 \\
PC7 & $1.08 \mathrm{E}-03$ & 0.05 & 0.88 \\
PC8 & $9.18 \mathrm{E}-04$ & 0.04 & 0.92 \\
PC9 & $8.32 \mathrm{E}-04$ & 0.04 & 0.96 \\
PC10 & $5.22 \mathrm{E}-04$ & 0.02 & 0.98 \\
PC11 & $3.74 \mathrm{E}-04$ & 0.02 & 1.00 \\
\hline
\end{tabular}

\section{DISCUSSION}

The MCF is related to, and interacts during growth and development with, the temporal lobes, the midface, and the mandible. It has been proposed that evolutionary transformations of the MCF, perhaps related to evolutionary modification of the temporal lobes, could have substantially influenced craniofacial morphology.
TABLE 3. Permutation tests, Procrustes distance (d), and significance levels

\begin{tabular}{llr}
\hline Compared groups & \multicolumn{1}{c}{$\mathrm{d}$} & $P$ value \\
\hline Humans / Neanderthals & 0.1508 & $<0.001$ \\
Humans / MPL & 0.121 & $<0.001$ \\
Humans / chimps & 0.22 & $<0.001$ \\
\hline
\end{tabular}

Our study confirms that modern humans are characterized by a uniquely derived configuration of the MCF. Additionally, it shows that this happened by at least 130 kyrs ago (Singa, 130 kyrs; Skuhl V, 100 kyrs; and Mladec 1, 35 kyrs). In particular, consistent with previous suggestions (Seidler et al., 1997; Lieberman et al., 2002) that modern humans have a relatively wider MCF, we provide evidence that the anterior MCF pole is more laterally placed in this group. Importantly with regard to facial retraction (see below), we demonstrate a relatively longer MCF, which results in a significant forward projection of the poles of the MCF and temporal lobes relative to the optic chiasm (canal of the optic nerve), the foramen rotundum (of the second branch of the trigemi- 
nal nerve), the base of the frontal lobes, the petrosal apex, and internal acoustic porus (Fig. 4).

Our findings support those of Spoor et al. (1999), Lieberman (2000) and Lieberman et al. (2002, 2004), all of which speculated that aspects of modern human craniofacial form may derive from a possible expansion of the MCF and the temporal lobe. Furthermore, we demonstrate that the relative anterior projection of the anterior MCF point is a significant autapomorphy of modern humans. Although our study includes no lateral landmarks (because this would require semilandmarks and surface analysis along the smoothly curving lateral and inferior wall-a study in progress) the warps of Figure 3 do suggest some mediolateral expansion of the MCF between the anterior MCF point and the maxillary and optical nerve foramina consistent with the findings of Seidler et al. (1997) and Lieberman et al. (2002).

It is important to note that these differences are not directly related to either absolute or relative brain size but reflect evolutionary changes in brain shape, possibly the temporal lobes within the MCF. Neanderthals with cranial capacities similar to modern humans (Ruff et al., 1997; Rightmire, 2004) display a significantly different MCF landmark configuration from that of modern humans. These findings suggest that brain evolution in modern humans and the Neanderthal lineage has proceeded differently from the putative ancestral condition.

These results raise several questions. First, do modern humans have larger temporal lobes than Neanderthals or $H$. heidelbergensis s.l.? And, second, are modern human temporal lobes in a different position with respect to other MCF structures? Although our study did not measure the size of the temporal lobe itself (because the brain is absent in fossils), and there is no significant difference in MCF size among living and fossil Homo taxa, there does appear to be a difference between humans and chimpanzees. It is possible that the lack of significance for the difference between modern and archaic humans may be due to small fossil sample size or a lack of correspondence between temporal lobe and MCF. However, it is interesting that we find no difference considering that absolute brain size is increased in modern humans and Neanderthals relative to Middle Pleistocene humans (Rightmire, 2004). This is especially so because our findings indicate a consistent shape difference between archaic (Neanderthals and Middle Pleistocene) and modern humans, suggesting functional modification in the latter. It seems likely that modifications of the lateral temporal lobes (not captured by our data) underlie the observed shape differences.

Several MRI studies have found that the temporal lobe in humans is approximately $20 \%$ larger relative to overall brain size than in apes, whereas the frontal lobes and the occipitoparietal block have undergone no relative expansion in human evolution (Semendeferi and Damasio, 2000; Rilling and Seligman, 2002; Rilling, 2006; but see Bruner et al., 2003). Within the temporal lobes it is held that the lateral and inferior areas in particular have undergone evolutionary modifications mostly related to language (Rilling, 2006). Lateral, caudal, and inferior parts of the temporal lobes are very different anatomically compared with nonhuman primates, which is likely related to human speech. The expanded lateral language areas have shifted visual pathways into a more lateral and caudal position in humans (Unger- leider et al., 1998). Additionally, there is an absolute and relative increase of white matter in humans that has been related to axons linking temporal and frontal cortical areas (Rilling and Seligman, 2002, Rilling, 2006). Thus, although no significant size difference is found between humans, this does not preclude significant shape differences being present due to functional modifications in later human evolution.

It is tempting to speculate that the anterolateral expansion of the MCF that we observe is secondary to changes in the temporal lobe and occurred with the origin of $H$. sapiens (Spoor et al., 1999; Lieberman et al., 2002), but this requires further detailed study of the basicranium and its complex surface morphology. While there is no doubt that basicranial morphology is influenced by the overall shape of the base of the brain (Moss, 1972; Richtsmeier et al., 2006), it is necessary to assess the detailed correspondence of surface morphologies between the soft tissue of the brain and the bony basicranium.

The relatively longer MCF of $H$. sapiens has important implications for the evolution of the modern human craniofacial morphology beyond the MCF. The skull of $H$. sapiens is characterized by facial reduction and other associated morphological features, such as an anteroposteriorly short midface and the presence of a chin (e.g., Day and Stinger, 1982; Schwartz and Tattersall, 2000; Lieberman et al., 2002; Rosas and Bastir, 2004; Bastir et al., 2007). The relatively anterior position of the MCF poles with respect to the optic and maxillary nerve foramina indicates that, compared with archaic humans, the posterior limit of the modern human midface (i.e., the maxillary tuberosities and the orbits) is shifted anteriorly in relation to several basicranial and neurocranial structures (Figs. 2-4). As noted by several researchers (Enlow, 1975; Enlow and Azuma, 1975; Bromage, 1992; Lieberman, 1998; Rosas, 2001; McCarthy and Lieberman, 2001) the posterior limit of the face is approximated in the midline of the cranium by the PM plane, defined as the midline projection of the line from the maxillary tuberosities to the most anterior point on the MCF.

The present findings show that modern humans are unique in possessing more forward projecting greater sphenoid wings (anterior limits of the MCF). This shifts the PM plane relatively anteriorly or rotates it clockwise when viewed from the right (for review, see McCarthy and Lieberman, 2001). In either case, the consequences for the evolution of modern human facial form are apparently significant, prompting the need for further studies examining the covariation of MCF form with facial and midline base form.

In terms of evolution, it is possible that greater sphenoid wing projection in modern humans is linked both to a rotation of the PM plane together with increased basicranial flexure. McCarthy and Lieberman (2001) showed that the lateral orbits and the PM plane are tightly integrated as a facial block. Because the top of the face is the floor of the anterior cranial base, and because the PM is nearly 90 degrees relative to the anterior cranial base, then a more flexed cranial base rotates the face as a whole ventrally under the anterior cranial fossa.

In addition, there is evidence that midline and lateral basicranial elements are relatively independent from each other in some respects (Baba et al., 2003; Bastir, 2004; Bastir and Rosas, 2005, 2006; Bastir et al., 2006). 
Greater sphenoid wing projection does not necessarily require modifications in basicranial flexure. This may account for the findings of Baba et al. (2003) that Sambungmacan 4 (SM4) has a degree of basicranial flexure fully within the range of modern humans, as do many other hominids (Ross and Henneberg, 1995), yet the MCF poles of SM4 are much shorter and similar to what we have found in archaic humans. Additionally, the archaic hominin from Bodo may manifest a very flexed midline cranial base while the lateral basicranium is morphologically primitive (Fig. 2). While the midline cranial base of Bodo may be taphonomically distorted, SM4 seems to be well preserved (Baba et al., 2003). It should be remembered, however, that cranial base angle is a very complex variable affected by brain size, cranial base length, face size, as well as many other factors (Lieberman et al., 2000; Ross et al., 2004; Jeffery, 2005). More research is needed to understand the determinants of basicranial flexure and the variation present among hominins.

Although this study has identified a clear evolutionary change in middle cranial fossa anatomy between archaic and modern humans that may well underlie key autapomorphies of the human face, more comparative and developmental studies are required. In particular, analyses of MRI and CT data could elucidate the morphological relationships of the brain and lateral basicranial surfaces and provide insights into how these basicranial elements interact with the face. Certainly, the findings of this study point to variations in the temporal lobe, which, through effects on the MCF and face, are central to the evolution of modern human facial form. Our findings link cognition and facial morphology in a perhaps unexpected way.

\section{ACKNOWLEDGMENTS}

We thank Antonio García Tabernero, Samuel García Vargas (Museo Nacional de Ciencias Naturales), Kornelius Kupzcik, Philipp Gunz, and Simon Neubauer (Max Planck Institute, Leipzig) for discussions and assistance with virtual anthropological methods and Fred Bookstein and Jim Rohlf for discussions. Two anonymous reviewers provided helpful comments. We thank Fred Spoor (University College London), Gerhard Weber (University of Vienna), Emma Mbua (Kenia National Museum), Roberto Macchiarelli (University of Poitiers), Luca Bondioli (Museo Pigorini, Rome), the Nespos Society (www.nespos.org), George Koufos (University of Thessaloniki), Maria Teschler-Nicola (NHM-Vienna), Robert Kruszynksi and Chris Stringer (NHM-London), Tom Schoenemann and Janet Monge (Penn Cranial CT collection) for help and permissions to access CT data, fossils, and stereolithographs in their care. We also thank Susan Taft and Michael Fagan (CMET, University of Hull) for help with CT-scanning.

\section{LITERATURE CITED}

Baba H, Aziz F, Kaifu Y, Suwa G, Kono RT, Jacob T. 2003. Homo erectus calvarium from the Pleistocene of Java. Science 299: 1384-1388.

Bastir M. 2004. A geometric morphometric analysis of integrative morphology and variation in human skulls with implications for the Atapuerca-SH hominids and the evolution of Neandertals.
Structural and systemic factors of morphology in the hominid craniofacial system. Madrid: Department of Anthropology, Autonoma University of Madrid.

Bastir M, O'Higgins P, Rosas A. 2007. Facial ontogeny in Neanderthals and modern humans. Proceedings of the Royal Society B: Biological Sciences 274:1125-1132.

Bastir M, Rosas A. 2005. The hierarchical nature of morphological integration and modularity in the human posterior face. Am J Phys Anthropol 128:26-34.

Bastir M, Rosas A. 2006. Correlated variation between the lateral basicranium and the face: a geometric morphometric study in different human groups. Arch Oral Biol 51:814-824.

Bastir M, Rosas A, Kuroe K. 2004. Petrosal orientation and mandibular ramus breadth: evidence of a developmental integrated petroso-mandibular unit. Am J Phys Anthropol 123:340-350.

Bastir M, Rosas A, O'Higgins P. 2006. Craniofacial levels and the morphological maturation of the human skull. J Anat 209:637654.

Biegert J. 1957. Der Formwandel des Primatenschadels und seine Beziehungen zur ontogenetischen Entwicklung und den phylogenetischen Spezialisationen der Kopforgane. Ggbrs Morph Jahrb 98:77-199.

Biegert J. 1963. The evaluation of characteristics of the skull, hands and feet for primate taxonomy. In: Washburn SL, editor. Classification and human evolution. Chicago: Aldine. p 116-145.

Bookstein FL. 1991. Morphometric tools for landmark data. Cambridge: Cambridge University Press.

Bromage TG. 1992. The ontogeny of Pan troglodytes craniofacial architectural relationships and implications for early hominids. J Hum Evol 23:235-251.

Bruner E, Manzi G, Arsuaga JL. 2003. Encephalization and allometric trajectories in the genus Homo. Evidence from the Neandertal and modern lineages. Proc Natl Acad Sci U S A 100: 15335-15340.

Cramon-Taubadel N, Frazier BC, Lahr M. 2007. The problem of assessing landmark error in geometric morphometrics: theory, methods, and modifications. Am J Phys Anthropol 134:24-35.

Dabelow A. 1931. Uber Korrelationen in der phylogenetischen Entwicklung der Schadelform II. Die Beziehungen zwischen Gehirn und Schadelbasisform bei den Mammaliern. Ggbrs Morph Jahrb 67:84-133.

Day MH, Stringer CB. 1982. A reconsideration of the Omo Kibish remains and the erectus-sapiens transition. In: Homo erectus et la Place de l'Homme et Tautavel parmi les Hominides Fossiles. Nice: Pretirages. p 814-846.

Deacon TW. 1997. What makes the human brain different? Annu Rev Anthrolpol 26:337-357.

Dryden IL, Mardia KV. 1993. Multivariate shape analysis. Sankya 55:460-480.

Enlow DH. 1975. The human face: an account of the postnatal growth and development of the craniofacial skeleton. New York: Harpers and Row.

Enlow DH. 1990. Facial growth. 3rd ed. Philadelphia; WB Saunders Company.

Enlow DH, Azuma M. 1975. Functional growth boundaries in the human and mammalian face. In: Bergsma D, Langman J, Paul NW, editors. Morphogenesis and malformation of the face and the brain. New York: Alan R. Liss. p 217-230.

Gould SJ. 1977. Ontogeny and phylogeny. London: Harvard University Press.

Good P. 1993. Permutation tests: a practical guide to resampling methods for testing hypotheses. New York: Springer-Verlag.

Gunz P, Mitteroecker P, Bookstein FL, Weber G. 2004. Computer aided reconstruction of incomplete human crania using statistical and geometrical estimation methods. Enter the past: computer applications and quantitative methods in archaeology. Oxford: BAR Int. Series 1227. p 92-94.

Hallgrimsson B, Lieberman DE, Liu W, Ford-Hutchinson AF, Jirik FR. 2007. Epigenetic interactions and the structure of phenotypic variation in the cranium. Evol Dev 9:76-91.

Hofer H. 1954. Die cranio-cerebrale Topographie bei den Affen. Homo 5:52-72. 
Hofer H, Tigges J. 1963. Studien zum Problem des Gestaltwandels des Schadels der Saugetiere insbesondere der Primaten. III. Zur Kenntnis der Hirnkyphosen. Z Morph Anthropol 54:115-126.

Holloway R, Broadfield DC, Yuan MS, editors. 2004. Brain endocasts - the paleoneurological evidence. New York: John Wiley \& Sons.

Jeffery N, Spoor F. 2002. Brain size and the human cranial base. Am J Phys Anthropol 118:324-340.

Jeffery N. 2003. Brain expansion and comparative prenatal ontogeny of the non-hominoid cranial base. J Hum Evol 45:263-284.

Jeffery N. 2005. Cranial base angulation and growth of the human fetal pharynx. Anat Rec 284A:491-499.

Jeffery N, Davies K, Kockenberger W, Williams S. 2007. Craniofacial growth in fetal Tarsius bancanus: brains, eyes and nasal septa. J Anat 210:703-722.

Kendall DG. 1989. A survey of the statistical theory of shape. Stat Sci 4:87-99.

Lahr MM. 1996. The evolution of modern human cranial diversity: a study in cranial variation. Cambridge: Cambridge University Press.

Lieberman DE. 1998. Sphenoid shortening and the evolution of modern human cranial shape. Nature 393:158-162.

Lieberman DE. 2000. Ontogeny, homology, and phylogeny in the hominid craniofacial skeleton: the problem of the browridge. In: Paul O'Higgins, Martin J. Cohen, eds. Development Growth and Evolution. Implications for the study of hominid skeleton. San Diego, London: Academic Press. p 86-122.

Lieberman DE, McCarthy RC. 1999. The ontogeny of cranial base angulation in humans and chimpanzees and its implication for reconstructing pharyngeal dimensions. J Hum Evol 36:487-517.

Lieberman DE, Ross C, Ravosa MJ. 2000. The primate cranial base, ontogeny, function, and integration. Yearbk Phys Anthropol 43:117-169

Lieberman DE, McBratney BM, Krovitz G. 2002. The evolution and development of cranial form in Homosapiens. Proc Natl Acad Sci U S A 99:1134-1139.

Lieberman DE, Krovitz GE, McBratney-Owen B. 2004. Testing hypotheses about tinkering in the fossil record: the case of the human skull. J Exp Zool 302B:284-301.

Maier W, Nkini A. 1984. Olduvay Hominid 9, New results of investigation. Cour Forsch Inst Senckenberg 69:123-130.

McCarthy R, Lieberman DE. 2001. Posterior maxillary PM plane and anterior cranial architecture in primates. Anat Rec 264:247-260.

Moss M. 1962. The functional matrix. In: Kraus B, Reidel R, editors. Vistas in orthodontics. Philadelphia: Lea and Febiger. p 85-98.

Moss ML. 1972. Twenty years of functional cranial analysis. Am J Phys Orthod 61:479-485.

O'Higgins P. 1999. Ontogeny and phylogeny: morphometric approaches to the study of skeletal growth and evolution. In: Chaplain MAJ, Singh GD, McLachlan J, editors. On growth and form, spatio-temporal patterning in biology. New York: John Wiley and Sons. p 373-393.

O'Higgins P. 2000. The study of morphological variation in the hominid fossil record, biology, landmarks and geometry. J Anat 197:103-120.

Richtsmeier JT, Aldridge K, DeLeon VB, Panchal J, Kane AA, Marsh JL, Yan P, Theodore M. Cole I. 2006. Phenotypic integration of neurocranium and brain. J Exp Zool 306B:360-78.

Rightmire G. 2004. Brain size and encephalization in early to MidPleistocene Homo. Am J Phys Anthropol 124:109-123.

Rilling JK. 2006. Human and nonhuman primate brains: are they allometrically scaled versions of the same design? Evol Anthropol 15:65-77.
Rilling JK, Seligman RA. 2002. A quantitative morphometric comparative analysis of the primate temporal lobe. J Hum Evol 42:129.

Rohlf FJ, Slice D. 1990. Extensions of the Procrustes method for the optimal superimposition of landmarks. Syst Zool 39:40-59.

Rosas A. 2001. Occurrence of neanderthal features in mandibles from the Atapuerca-SH Site. Am J Phys Anthropol 114:7491.

Rosas A, Bastir M. 2004. Geometric morphometric analysis of allometric variation in the mandibular morphology from the hominids of Atapuerca, Sima de los Huesos Site. Anat Rec 278A:551560.

Rosas AM, Bastir C, Martinez-Maza C, Garcia-Tabernero A, Lalueza-Fox C. 2006. Inquiries into Neanderthal cranio-facial development and evolution, 'accretion' vs 'organismic' models. In: Harrison T, Harvati K, editors. Neanderthals revisited. New York: Springer Verlag. p 38-69.

Ross CF, Ravosa MJ. 1993. Basicranial flexion, relative brain size, and facial kyphosis in nonhuman primates. Am J Phys Anthropol 91:305-324.

Ross C, Henneberg M. 1995. Basicranial flexion, relative brain size, and facial kyphosis in Homo sapiens and some fossil hominids. Am J Phys Anthropol 98:575-593.

Ross CF, Henneberg M, Ravosa MJ, Richard S. 2004. Curvilinear, geometric, and phylogenetic modeling of basicranial flexion: is it adaptive, is it constrained? J Hum Evol 46:185-213.

Ruff CB, Trinkaus E, Holliday TW. 1997. Body mass and encephalization in Pleistocene Homo. Nature 387:173-176.

Schwartz JH, Tattersall I. 2000. The human chin revisited: what is it and who has it? J Hum Evol 38:367-409.

Seidler H, Falk D, Stringer C, Wilfing H, Muller GB, zur Nedden D, Weber GW, Reicheis W, Arsuaga JL. 1997. A comparative study of stereolithographically modelled skulls of Petralona and Broken Hill: implications for future studies of middle Pleistocene hominid evolution. J Hum Evol 33:691-703.

Semendeferi K, Damasio H. 2000. The brain and its main anatomical subdivisions in living hominoids using magnetic resonance imaging. J Hum Evol 38:317-332.

Shea BT. 1985. On aspects of skull form in African Apes and orangutans, with implication for hominoid evolution. Am J Phys Anthropol 68:329-342.

Slice DE. 1998. Morpheus et al.: software for morphometric research. Revision 1-30-98-beta. Department of Ecology and Evolution, State University of New York, Stony Brook.

Spoor F. 1997. Basicranial architecture and relative brain size of Sts5 (Australopithecus africanus) and other Plio-Pleistocene hominids. S Afr J Sci 93:182-186.

Spoor F, O'Higgins P, Dean C, Lieberman DE. 1999. Anterior sphenoid in modern humans. Nature 397:572.

Stringer CB. 2001. Modern human origins: progress and prospects. Philos Trans R Soc Lond B 357:563-579.

Ungerleider LG, Courtney SM, Haxby JV. 1998. A neural system for human visual working memory. Proc Natl Acad Sci U S A 95:883-890.

Weidenreich F. 1941. The brain and its role in the phylogenetic transformation of the human skull. Trans Am Philos Soc 31:321442.

Zelditch ML, Swiderski DL, Sheets HD, Fink WL. 2004. Geometric morphometrics for biologists: a primer. San Diego: Elsevier Academic Press.

Zola SM, Squire IR, Teng E, Stefanacci L, Buffalo EA, Clark R. 2000. Impaired recognition memory in monkeys after damage limited to the hippocampal region. J Neurosci 20:451-463. 